\title{
Introduction: Working Toward Diversity
}

Every Other Thursday focuses on women scientists who created an association to help one another through the complexities and stresses of their competitive careers. In the I970s, when the group started, choosing such a career frequently meant being the first or only woman in a department or research organization. Today, as the numbers of women in science and engineering have increased, such extreme isolation and obvious groundbreaking is less likely. Are the struggles of these women and the lessons they learned therefore only of historical interest today? The answer is an unequivocal no, for several reasons. First, analysis of the numbers of women advancing to top levels in their careers shows that a gender differential persists. In-depth studies on career progression and the environment women experience in the work- 
place demonstrate that very real barriers remain. Furthermore, it is clear that members of racial and ethnic minorities share many of the effects of isolation that women have experienced and with which they still struggle.

Despite progress toward equity, important disparities still exist. Although this volume attempts neither to be an authoritative source of data nor to determine causes of discrimination and underrepresentation of women in science, key studies provide a current context for the message of this book.

A primary source of the power of the group process is that groups bring together people with shared concerns who might otherwise be isolated from one another. Data on the representation of women illustrate this point. (The numbers for other minorities are still more striking.) In 1999, women earned ${ }_{3} 6$ percent of doctoral degrees granted in science and engineering (up from 8 percent in 1973). Yet only 26 percent of employed doctoral scientists and engineers were women. Of those employed in four-year colleges and universities, 29 percent of the doctoral scientists and engineers were women. Within academia, the percentages decrease when tenured or full professors are considered and when the most prestigious research institutions are examined. A publication entitled "A National Analysis of Diversity in Science and Engineering Faculties at Research Universities" looks at the representation of women in fifty top research universities. ${ }^{1}$ The authors discovered that 7.6 percent of full profes- 
sors in chemistry and I 4.8 percent in biological sciences were women. The numbers were even lower for mathematics, physics, and all branches of engineering. In sociology and psychology, the fields having the highest percentage of women faculty, there was still a striking contrast between assistant professors ( 52 and 45 percent, respectively) and full professors (I4 percent in both fields). Abigail Stewart, project director at the Institute for Research on Women and Gender at the University of Michigan, has pointed out that "many smart motivated women have cited isolation and marginalization as reasons for moving out of science and engineering at major research institutions." To extend the point to fields outside academia, it is interesting to note that as of $200 \mathrm{I}$ only four of the CEOs of Fortune 500 companies were women. ${ }^{2}$

That women have lagged behind men in their representation in the science and engineering workforce is of much concern to organizations that seek to foster scientific achievement. In researching the issue, I discovered that the situation is worse than I had imagined.

The administration and faculty at Massachusetts Institute of Technology (MIT) performed the first and most famous in-depth study on the status of women faculty within a particular institution. A group of senior women on the faculty had gathered preliminary evidence that they had less laboratory space, less access to research funding, and lower salaries than their male counter- 
parts. In addition, they were infrequently represented on committees that made decisions about hiring and research funding. MIT's administration responded by researching the charges, finding that they were accurate, and taking steps to correct the inequities. The abstract to their report is an excellent description of the issues that still confront women scientists and analysis of why they went unrecognized by administration as well as by the women themselves. ${ }^{3}$

In 1995 the Dean of Science established a Committee to analyze the status of women faculty in the six departments in the School of Science. The Committee submitted a report of its findings in August 1996 and amended reports in I 997 and I998. The Committee discovered that junior women faculty feel well supported within their departments and most do not believe that gender bias will impact their careers. Junior women faculty believe, however, that family-work conflicts may impact their careers differently from those of their male colleagues. In contrast to junior women, many tenured women faculty feel marginalized and excluded from a significant role in their departments. Marginalization increases as women progress through their careers at MIT. Examination of data revealed that marginalization was often accompanied by differences in salary, space, awards, resources, and response to outside 
offers between men and women faculty with women receiving less despite professional accomplishments equal to those of their male colleagues. An important finding was that this pattern repeats itself in successive generations of women faculty. The Committee found that, as of I994, the percent of women faculty in the School of Science (8\%) had not changed significantly for at least io and probably 20 years. The Committee made recommendations for improving the status of senior women faculty, addressing the family-work conflict for junior women faculty, and increasing the number of women faculty. The Dean of Science took immediate actions to effect change and these have already resulted in highly significant progress including an increase in the number of women faculty. This collaboration of faculty and administration could serve as a model for increasing the participation of women, and also of under-represented minorities, on the faculty of other Schools at MIT. This is an important initiative since, even with continued effort of this magnitude, the inclusion of substantial numbers of women on the Science and Engineering faculties of MIT will probably not occur during the professional lives of our current undergraduate students. The inclusion of significant numbers of minority faculty will lag for even longer because of the additional problem of a shortage of minority students in the pipeline. 
A study of the persistent gender gap in the science and engineering workforce by the National Research Council (NRC) concluded that "while women are now visible in fields in which they were virtually absent 25 years ago . . . they continue to cast a very small shadow." Finding that "at any age women lag behind their male colleagues in career advancement," the report discusses conditions that slow or interrupt careers, childbearing and rearing being the most obvious but not the only factors. An analysis of salaries shows that a gap also persists there, even when the data are broken down to compare only "groups that are as comparable as possible." For example, there is still an I I percent gap in salary between men and women who are full professors. Because of conflicts with family responsibilities, women may choose lower-paying jobs that have greater nonsalary rewards such as time flexibility. ${ }^{4}$

Discussing the effects on career outcomes of being in a minority, the authors of the NRC study (Scarcity to Visibility) comment, "A given field . . . may need at least a minimum number of women before these women attain a critical mass whereby they are no longer viewed as an oddity. Having a critical mass can minimize socialization difficulties otherwise encountered in a male-dominated environment." Many studies noting the attrition of women from science at every stage of education and promotion suggest the lack of role models as one cause. (In the case of ethnic minorities the disparity is even greater, so that a Black 
or Hispanic individual, male or female, is very likely to go through training without a single role model of his or her ethnicity.) Dr. Debra Rolison of the Naval Research Laboratory postulated that "a very plausible case can be made that academic departments are an unhealthy-even hostile-environment for women." Professor Janet Osteryoung, director of the Division of Chemistry at the National Science Foundation, described the reaction of young women to what they see: "Women who are eligible for faculty positions have earned a Ph.D. in a chemistry department. They have absorbed the tone of that environment . . . and have decided they don't want any more of it."5

On January I4, 2005, Lawrence Summers, president of Harvard University, spoke at a conference on women and minorities in science organized by the National Bureau of Economic Research (NBER). He cited studies showing that more boys than girls score at the high and low ends of standardized math and science tests and suggested that this could explain the larger number of men at the top of the professional ladder in these fields. He specifically stated his belief that this difference in "availability of aptitude at the high end" had a greater impact than social factors and discrimination on the underrepresentation of women. ${ }^{6}$

Among the flaws in Summers' analysis were the lack of evidence that genetic factors are responsible for the difference in test scores and the substantial evidence that test-score differences do not correlate well with success in the professions. Par- 
ticipants in the conference noted that they had been listening throughout the day to complex and careful studies demonstrating the role of discrimination and socialization. In this context, Summers' comments seemed careless and gratuitous in light of the chilling effect they would doubtless have on efforts to combat discrimination, coming from someone in his prominent position. Dr. Yu Xie, a sociologist from the University of Michigan (present at the conference), whose work Dr. Summers had cited, said that his data had been misinterpreted. Xie stated that the inference that the underrepresentation of women in the top ranks of science and math could be due to differences in ability was an illogical leap. Research shows that even women at the highest levels of mathematical achievement are less likely than their male peers to pursue math and science careers. Xie and others also noted that over the past few decades there has been a steady increase in women's participation in the sciences and engineering. Because the genetic pool has not changed in that time, factors like improved educational conditions for women and efforts to reduce discrimination are much likelier explanations. ${ }^{7}$

Summers introduced his remarks by saying that he had made "an effort to think in a very serious way about" the lack of women in the higher echelons of math and science. Citing areas that might be studied in the same way, he observed that "white men are very substantially underrepresented in the National Basketball Association; and that Jews are very substantially underrepre- 
sented in farming and in agriculture." In a letter of apology written a month later, he said, "My January remarks substantially understated the impact of socialization and discrimination, including implicit attitudes - patterns of thought to which all of us are unconsciously subject. The issue of gender difference is far more complex than comes through in my comments, and my remarks about variability went beyond what the research has established."8

It was perhaps most unsettling that those who protested Summers' comments were accused of trying to stifle scientific debate and of demanding politically correct speech that precluded suggestions of genetic differences. An organizer of the conference suggested that the critics were activists whose sensibilities might be at odds with intellectual debate. In this way the important discussion of prejudice leading to scientifically invalid claims was partly submerged in an uproar about free speech that missed the point at hand. ${ }^{9}$

The extensive discussion following Summers' remarks did appear to have a positive result - the mobilization of scientists and sociologists to set the record straight and to communicate concerns about the suggestion that underrepresentation of certain groups had inevitable natural causes. This discussion will benefit not only women but also other groups who do not find science and engineering fields hospitable. A letter to Science magazine signed by more than eighty scientists concludes: "We must con- 
tinue to address the multitude of small and subtle ways in which people of all kinds are discouraged from pursuing interest in scientific and technical fields. Society benefits most when we take full advantage of the scientific and technical talent among us. It is time to create a broader awareness of those proven and effective means, including institutional policies and practices, that enable women and other underrepresented groups to step beyond the historical barriers in science and engineering." 10

In this context, the formation of problem-solving groups could contribute significantly to overcoming barriers to participation in any profession. The stories of the women in Every Other Thursday and the strategies they developed to achieve success and balance attest to the effectiveness of the group process. 